\title{
On the relationship of energetic particle precipitation and mesopause temperature
}

\author{
Florine Enengl $^{1,2,3,4}$, Noora Partamies ${ }^{2,5}$, Nickolay Ivchenko ${ }^{1}$, and Lisa Baddeley ${ }^{2,5}$ \\ ${ }^{1}$ Division of Space and Plasma Physics, KTH Royal Institute of Technology, Stockholm, Sweden \\ ${ }^{2}$ Department of Arctic Geophysics, The University Centre in Svalbard, Longyearbyen, Norway \\ ${ }^{3}$ Space Environment and Effects Section, European Space Agency, Noordwijk, the Netherlands \\ ${ }^{4}$ Department of Physics, University of Oslo, Oslo, Norway \\ ${ }^{5}$ Birkeland Centre for Space Science, Bergen, Norway
}

Correspondence: Florine Enengl (florine@kth.se)

Received: 30 June 2020 - Discussion started: 15 July 2020

Revised: 13 August 2021 - Accepted: 16 August 2021 - Published: 9 September 2021

\begin{abstract}
Energetic particle precipitation (EPP) has the potential to change the neutral atmospheric temperature in the mesopause region. However, recent results are inconsistent, leaving the mechanism and the actual effect still unresolved. In this study we have searched for electron precipitation events and investigated a possible correlation between Dregion electron density enhancements and simultaneous neutral temperature changes. The rotational temperature of the excited hydroxyl $(\mathrm{OH})$ molecules is retrieved from the infrared spectrum of the $\mathrm{OH}$ airglow.

The electron density is monitored by the European Incoherent Scatter Scientific Association (EISCAT) Svalbard Radar. We use all available experiments from the International Polar Year (IPY) in 2007-2008 until February 2019. Particle precipitation events are characterized by rapid increases in electron density by a factor of 4 at an altitude range of 80-95 km, which overlaps with the nominal altitude of the infrared $\mathrm{OH}$ airglow layer. The $\mathrm{OH}$ airglow measurements and the electron density measurements are co-located. Six of the 10 analysed electron precipitation events are associated with a temperature decrease of 10-20 K. Four events were related to a temperature change of less than $10 \mathrm{~K}$.

We interpret the results in terms of the change in the chemical composition in the mesosphere. Due to EPP ionization the population of excited $\mathrm{OH}$ at the top of the airglow layer may decrease. As a consequence, the airglow peak height changes and the temperatures are probed at lower altitudes. The observed change in temperature thus depends on the behaviour of the vertical temperature profile within the airglow
\end{abstract}

layer. This is in agreement with conclusions of earlier studies but is, for the first time, constructed from electron precipitation measurements as opposed to proxies. The EPP-related temperature change recovers very fast, typically within less than $60 \mathrm{~min}$. We therefore further conclude that this type of EPP event reaching the mesopause region would only have a significant impact on the longer-term heat balance in the mesosphere if the lifetime of the precipitation was much longer than that of an EPP event (30-60 min) found in this study.

\section{Introduction}

Space weather phenomena can affect the dynamics and the heat balance of the atmosphere by depositing energy in the form of energetic particle precipitation (EPP). In particular, investigating the mesopause region (at $80-100 \mathrm{~km}$ ), the boundary between the mesosphere and the thermosphere (Andrews, 2010), is important.

Within this boundary, the behaviours of neutral gas and ionized particles differ, which is why complex interactions between dynamics, photochemistry, heating and transport mechanisms take place and the atmospheric energy budget can be altered.

Several studies have investigated the effects of EPP on neutral temperatures in the mesopause region. Nesse Tyssøy et al. (2010) compared particle precipitation observed by the NOAA (National Oceanic and Atmospheric Administration) 
POES (Polar Orbiting Environmental Satellites) MEPED (Medium Energy Proton and Electron Detectors) instrument with neutral temperatures derived from the TIMED (Thermosphere, Ionosphere, Mesosphere, Energetics and Dynamics) satellite's SABER (Sounding of the Atmosphere using Broadband Emission Radiometry) instrument. They used a data set of $80 \mathrm{~d}$ within May-June and October-November in 2003 over the Northern Hemisphere. Temperature profiles were averaged over all local time hours for four flux levels of precipitating energetic protons. A temperature increase of about $40 \mathrm{~K}$ was found at $115-120 \mathrm{~km}$ associated with strong fluxes of 80-250 keV protons in October-November (Northern Hemisphere early winter). The strongest temperature increase of 15-20 K in May-June (Northern Hemisphere early summer) at the altitudes of $110-115 \mathrm{~km}$ was reported due to high fluxes of $30-80 \mathrm{keV}$ protons. As particle precipitation events change the Pedersen conductivity, Joule heating may contribute to the increase in temperature at these altitudes. Further down in the atmosphere, at $85-90 \mathrm{~km}$, a cooling of 3-4 K during periods of high $\mathrm{Kp}$ values was observed due to precipitation of $250-800 \mathrm{keV}$ protons (an intense solar proton event in the period of 27 October-6 November 2003).

The rotational hydroxyl $(\mathrm{OH})$ airglow temperature was observed during six nights of the austral winter in 2008 by Suzuki et al. (2010b). These nights were selected to include high auroral activity and clear weather. In their study, the temperature was derived from spectra recorded at Syowa Station in Antarctica by a high-sensitivity spectrometer. During only one of these nights (27-28 March 2008), an increase in the temperature of $10 \mathrm{~K}$ over a time period of $15 \mathrm{~min}$ was observed. Furthermore, a decrease in the relative intensity of the $\mathrm{OH}(8-4) Q$ branch of $\sim 23 \%$ was found by comparing the pre-EPP level to that half an hour after the lowest local minimum of the horizontal $H$ component. No such coherent behaviour was seen during the other nights. Suzuki et al. (2010b) suggested a relationship between EPP and the OH temperature based on measured disturbances in the horizontal magnetic field and variations in the cosmic radio noise absorption (CNA) over the course of several hours of geomagnetic activity. The average energy of the precipitating electrons during this night reached $10-20 \mathrm{keV}$. They discussed different mechanisms for causing the change in the temperature. Joule heating was concluded to not contribute much, as the estimated heating rate required to explain the observed temperature increase at the mesopause height was 3 orders of magnitude higher than the heating rate the particle precipitation observations suggested. Direct particle heating, on the other hand, is produced by precipitating particles colliding with the atmospheric neutrals. This heating process is dependent on the incident particle energy and their deposition altitude. Similarly to the Joule heating, the authors estimated the energy deposition rate of EPP at the mesopause height and concluded that the high-energy particle flux required to explain the temperature change was unrealistically high. Atmospheric gravity waves were also excluded, as the intensity of the $\mathrm{OH}$ airglow and the rotational temperature did not show a positive correlation, which is characteristic of dynamics-driven conditions, as described and modelled by Cho and Shepherd (2006). Suzuki et al. (2010b) further discussed the possibility of a change in the height distribution of the $\mathrm{OH}$ airglow emission during auroral events. The initial profile of $\mathrm{OH}$ volume emission rates retrieved by the SABER instrument onboard the TIMED satellite was compared to an example of the disturbed layer. The comparison showed a decrease in the upper part of the disturbed layer as the thickness of the $\mathrm{OH}$ layer had decreased by $20 \%$. If a change in the height distribution of the $\mathrm{OH}$ airglow emission occurred during an auroral event, an increase in temperature is not necessarily observed, as the outcome would depend on the local temperature in the mesosphere.

The connection between the geomagnetic activity and the long-term temperature in the mesopause region during solar cycles 23 and 24 was studied by Gavrilyeva and Ammosov (2018). The $\mathrm{OH}$ rotational temperature was measured by the ground-based infrared spectrograph at Maimaga station $\left(63^{\circ} \mathrm{N}, 129.5^{\circ} \mathrm{E}\right)$ and ascribed to an altitude of $87 \mathrm{~km}$, which is commonly assumed to be the peak height of the $\mathrm{OH}$ layer. The seasonally averaged temperatures from 1999 to 2015 were included in the analysis. The results showed that the winter mesopause temperature from October to February is about $10 \mathrm{~K}$ higher during the years with high geomagnetic activity $(\mathrm{Ap}>8)$ than during low geomagnetic activity years $(A p \leq 8)$. This suggests a correlation between the mesopause temperatures and the solar activity. A more direct solar activity dependence of $\mathrm{OH}$ airglow temperatures was reported by Holmen et al. (2014). They concluded on a temperature change of about $4 \mathrm{~K}$ per 100 solar flux units (SFUs) of the F10.7 radio flux. The question of the short-term relationship between EPP and the mesopause temperature was still left open.

The purpose of this study is to characterize the effect of the EPP on the mesopause temperature in more detail using co-located measurements of precipitating electrons and the mesospheric temperature. The instrumentation is further described in Sect. 2. Section 3 outlines the data used in this study as well as the analysis of the European Incoherent Scatter Scientific Association (EISCAT) Svalbard Radar data. Finally, the results are shown and discussed in Sects. 4 and 5. The conclusions of our findings are summarized in Sect. 6 .

\section{Instrumentation}

Following Cresswell-Moorcock et al. (2013), we use the EISCAT Svalbard Radar data to identify electron precipitation events as electron density enhancements. Simultaneous and co-located neutral temperature measurements are determined from $\mathrm{OH}$ airglow spectra collected by a spectrometer. The derived rotational $\mathrm{OH}$ temperatures are taken as the neutral temperature of the mesopause region, assuming that the ex- 
cited $\mathrm{OH}$ molecules are in thermal equilibrium with the ambient atmosphere.

\subsection{EISCAT Svalbard Radar}

For this study the EISCAT Svalbard Radar (ESR, Wannberg et al., 1997) in Longyearbyen, Norway (situated at a geographic latitude of $78.15^{\circ} \mathrm{N}$ and a geographic longitude of $16.02^{\circ} \mathrm{E}$ and at corrected geomagnetic coordinates of $75.43^{\circ} \mathrm{N}$ and $110.68^{\circ} \mathrm{E}$ ), is used. The radar operates at the $500 \mathrm{MHz}$ band and has a $32 \mathrm{~m}$ steerable parabolic dish antenna and a $42 \mathrm{~m}$ fixed parabolic antenna aligned with the local geomagnetic field. For the purpose of this study, we searched for experiments with good height resolution (less than $5 \mathrm{~km}$ ) at mesopause altitudes. The "manda" experiment (Tjulin, 2017) resolves altitudes of 80 to $100 \mathrm{~km}$ with 1-2 km height resolution and was therefore chosen for the radar campaign in January and February 2019 for this study. In addition to our experiment and all previously run manda, all previous "ipy" experiments were also investigated, as ipy covers the mesopause region with a vertical resolution of $4-5 \mathrm{~km}$. The manda experiments utilize the $32 \mathrm{~m}$ dish, and the ipy data are collected on the $42 \mathrm{~m}$ dish.

\subsection{Ebert-Fastie airglow spectrometer}

The Ebert-Fastie spectrometer at the Kjell Henriksen Observatory (KHO) in Longyearbyen is used to retrieve the winter temperature of the mesopause (Sigernes et al., 2003). The observatory is located only a kilometre away from the radar site, so it is practically co-located. The spectrometer scans the near-infrared wavelength region from 824 to $871 \mathrm{~nm}$ which includes the rotational-vibrational $\mathrm{OH}(6-2)$ band of the $\mathrm{OH}$ airglow. The spectrometer points to the zenith with a field of view of $5^{\circ}$. It measures whenever the Sun is more than $12^{\circ}$ below the horizon, which at $\mathrm{KHO}$ latitude $\left(78.2^{\circ} \mathrm{N}\right)$ gives an optical observation season from the beginning of November until the end of February. The spectral resolution of the spectrometer measurement of the $\mathrm{OH}(6-2)$ band is $0.4 \mathrm{~nm}$. One scan takes $25 \mathrm{~s}$, but to obtain a good signal-to-noise ratio, many scans are averaged during post-processing of the data. Most earlier studies use $1 \mathrm{~h}$ averages (144 scans). In this study, half-hour averaging (72 scans) is used for better temporal resolution. Improving the temporal resolution reduces the signal-to-noise ratio, which is reflected by larger temperature errors. It is justified by the aim of studying shortterm temperature changes. For the events analysed in this study, the selection of "good" data still uses the same criteria that were earlier applied to hourly averaged data. We further move the $30 \mathrm{~min}$ averaging window by $10 \mathrm{~min}$ time steps to obtain a smoothed temporal evolution of temperature. The rotational $\mathrm{OH}$ temperatures are obtained by fitting a synthetic spectrum to the measured band of emission lines. Using the intensities of four emission line pairs $\left(P_{1}\right.$ and $\left.P_{2}\right)$ within the $P$ branch of $\mathrm{OH}(6-2)$, the slope of the best fit determines the temperature. An auroral emission line from atomic oxygen at $844.6 \mathrm{~nm}$ lies in the middle of the $\mathrm{OH}(6-$ 2) spectrum. The times when that emission intensity overtakes the $\mathrm{OH}$ emission intensity (fit covariance greater than 0.5 ) are excluded in the temperature analysis due to an inaccurate fit. Other things causing poor fits and missing temperature values are cloudiness, high background illumination (e.g. scattered moonlight) or technical issues with the instrument. The threshold values for the fit variances have been determined empirically by viewing and fitting large data sets over decades. For consistency, at the event selection state we have employed the same threshold values as the earlier work by Sigernes et al. (2003) and Holmen et al. (2013). Once the EPP events were selected, we relaxed the threshold values to obtain a more continuous data coverage. The covariance threshold was lowered to 0.2 as long as the fit variance criteria were still met. Similarly, the fit variance threshold value for $P_{2}$ lines was increased from 0.3 to 1.0 as long as the covariance $(<0.5)$ and $P_{1}$ line $(<0.05)$ criteria held. The uncertainties introduced by this procedure are reflected by the error bars in the displayed data. The accuracy of the fitting method in estimating rotational temperatures is $\pm 2 \mathrm{~K}$. The temperature error corresponds to the Boltzmann plot least square fit error and is typically somewhat larger than the uncertainty of the method itself (see values in Table 1). In addition to the fitted temperature values, we use relative band brightness (non-calibrated arbitrary units) of the $P$ branch of the $\mathrm{OH}(6-2)$ transition. These intensity values are routinely calculated and saved together with the rotational temperatures.

\section{Data description and event selection}

A total of $10220 \mathrm{~h}$ of ESR data were initially inspected. The ipy and manda experiments contribute 10144 and $76 \mathrm{~h}$ of data respectively. These experiments provide a sufficient height resolution $(<5 \mathrm{~km})$ to detect enhanced electron densities in the mesopause region. Here the mesopause region is defined from an altitude range of 80 to $100 \mathrm{~km}$ to include the hydroxyl $(\mathrm{OH})$ peak height at $76-90 \mathrm{~km}$ (Mulligan et al., 2009). The chosen experiments are run either in the geomagnetic field-aligned direction ( $42 \mathrm{~m}$ : ipy, $32 \mathrm{~m}$ : manda) or with vertical pointing ( $32 \mathrm{~m}$ : manda). The data set starts from the International Polar Year (IPY) in 2007-2008 when ESR was run continuously from 1 March 2007 to 29 February 2008 (Blelly et al., 2010). This IPY includes $8784 \mathrm{~h}$ of the ipy experiment. Additionally, all manda and ipy experiments from December, January and February since the IPY until February 2019 are included in the event search. The total of $1388 \mathrm{~h}$ of ESR data between 2008 and 2019 was used to search for EPP events. Finally, the ESIRI experiment (ESR Ionospheric D-Region Experiment for Investigation of EPP) manda mode was run for a total of $48 \mathrm{~h}$ in January $(24 \mathrm{~h})$ and February 2019 (another $24 \mathrm{~h}$ ) to specifically collect data for 
this study. The experiment was run for six evenings between 16:00 and 22:00 UT (19:00 to 01:00 MLT).

The EISCAT raw data files (auto-correlation functions - ACFs) are analysed using the GUISDAP data package (Lehtinen et al., 1996). This provides an iterative fitting of the ACFs to produce the electron densities examined in this study. The post-integration time is $60 \mathrm{~s}$. Data gaps are shown by white areas in the plots (Figs. 1 and 2) and occur where GUISDAP has not managed to provide a fit; $10 \mathrm{~min}$ averaged electron densities are calculated for the altitude ranges of 87-90 and 91-94 km separately. The electron density measurements become too noisy towards the lower part of the airglow layer, so we chose to only include the heights overlapping with the top part of the airglow layer. The error of the electron density is averaged to give a mean error for further analysis.

The search for the EPP events in the radar data is based on an earlier study by Cresswell-Moorcock et al. (2013) in which onsets were found as sudden increases (a factor 5 over $5 \mathrm{~min}$ ) in electron density median values. For this study the electron density is averaged to $10 \mathrm{~min}$ resolution with an altitude resolution of $4 \mathrm{~km}$. The previous study's factor of 5 was attempted, but since there were a number of events just below this threshold, the factor was adjusted to 4 . We thus searched for an increase in electron density by a factor of 4 within $20 \mathrm{~min}$. If onsets were found only $10 \mathrm{~min}$ apart, the latter onset was ignored.

The events were detected automatically but inspected and classified visually based on the temporal evolution of the electron density and the $\mathrm{OH}$ temperature. Events with large electron density errors of more than $5 \times 10^{9} \mathrm{~m}^{-3}$ were excluded. Events which lack more than one temperature measurement at or after the onset were also excluded. Events which show a particle precipitation signature of electron density enhancement through the whole ionospheric column $(87-126 \mathrm{~km})$ were sorted into the EPP category. Events which show an electron density enhancement limited to the horizontal layer at the bottom of the E region (around $100 \mathrm{~km}$ ) were categorized as sporadic E layers (Rapp et al., 2011). The remaining data not showing clear EPP or sporadic E-layer behaviour were excluded from the analysis. The sporadic E-layer events are not discussed further in this paper. This selection process resulted in a set of 10 EPP events, which were categorized into groups of increasing, decreasing and stable (no change) temperature evolution over the EPP onset.

The electron density during the radar run on 6 January 2019 from 16:00 to 22:00 UT is shown in Fig. 1a. The onset of the EPP took place at 19:50 UT and the event lasted until 20:20 UT. The background electron density in the lower part of the ionosphere (below $100 \mathrm{~km}$ ) prior to the EPP onset was low (below $\sim 10^{10} \mathrm{~m}^{-3}$ ) but abruptly increased at the EPP onset time from the pre-EPP value to a local maximum in $10 \mathrm{~min}$. The $\mathrm{OH}$ rotational temperature (panel b) experiences large variations $(\sim 20 \mathrm{~K})$ during the hours leading to the precipitation onset, when there are no electron density enhancements below $100 \mathrm{~km}$ altitude. A small temperature $\operatorname{dip}(\sim 5 \mathrm{~K})$ is seen $10 \mathrm{~min}$ after the onset, but the change is well within the measurement uncertainties and does not persist. The relative $\mathrm{OH}$ band brightness (panel c) minimized half an hour before the precipitation started and remained at that level until half an hour after the EEP onset. During this experiment the radar was pointed to zenith.

\section{Results}

Our 10 EPP events are listed in Table 1. The criterion for a changing mesopause temperature is that the change is larger than the uncertainty of the temperatures averaged over half an hour. However, following the analysis by Suzuki et al. (2010b) where temperature variability less than $10 \mathrm{~K}$ is considered minor and that larger than $10 \mathrm{~K}$ is considered significant, we additionally include the second event in the class of "decreasing" temperatures, despite the large uncertainties. An event is classified as stable (no change) if the temperature change from the value just before the onset to that $20 \mathrm{~min}$ after the onset time is a minor temperature change and within the uncertainty of the averaged temperatures. As each of the data points is an average over the previous $30 \mathrm{~min}$, the point just prior to the onset is a representative of the temperature level before the precipitation starts, while the temperature value $20 \mathrm{~min}$ after the onset includes onset time information as well as any immediate changes after the onset.

Apart from the ninth and tenth events, all other events were measured by a field-aligned pointing radar experiment. Thus, the auroral emission does not obscure the temperature calculations as the two parameters were often measured side by side rather than in exactly the same column. The events associated with a temperature decrease (six events) show a change from 10 to $40^{\circ}$, while events with a temperature increase (four events) only undergo a few degrees' change and are thus classified as stable.

Figure 2 displays each individual EPP event. The left panels present electron density measurements as a function of time and altitude for a $6 \mathrm{~h}$ interval centred at the EPP onset. The right column includes the temporal evolution of the Dregion electron density (top panel), the airglow temperature (middle panel) and the relative $\mathrm{OH}(6-2)$ band intensity (bottom panel). In the line plots the electron densities are from the lowest height range, where the increase by a factor of 4 was detected.

Brief descriptions of each event are given in the following paragraphs.

- The first event commences at 23:30 UT on 29 December 2007 and is detected in the altitude range of 91$94 \mathrm{~km}$. The electron density at the EPP event start time is $1.0 \times 10^{10} \mathrm{~m}^{-3}$. The increased precipitation electron flux lasts for about $30 \mathrm{~min}$. The mesopause temperature decreases by $40 \mathrm{~K}$ (from 225 to $185 \mathrm{~K}$ ) over the EPP 


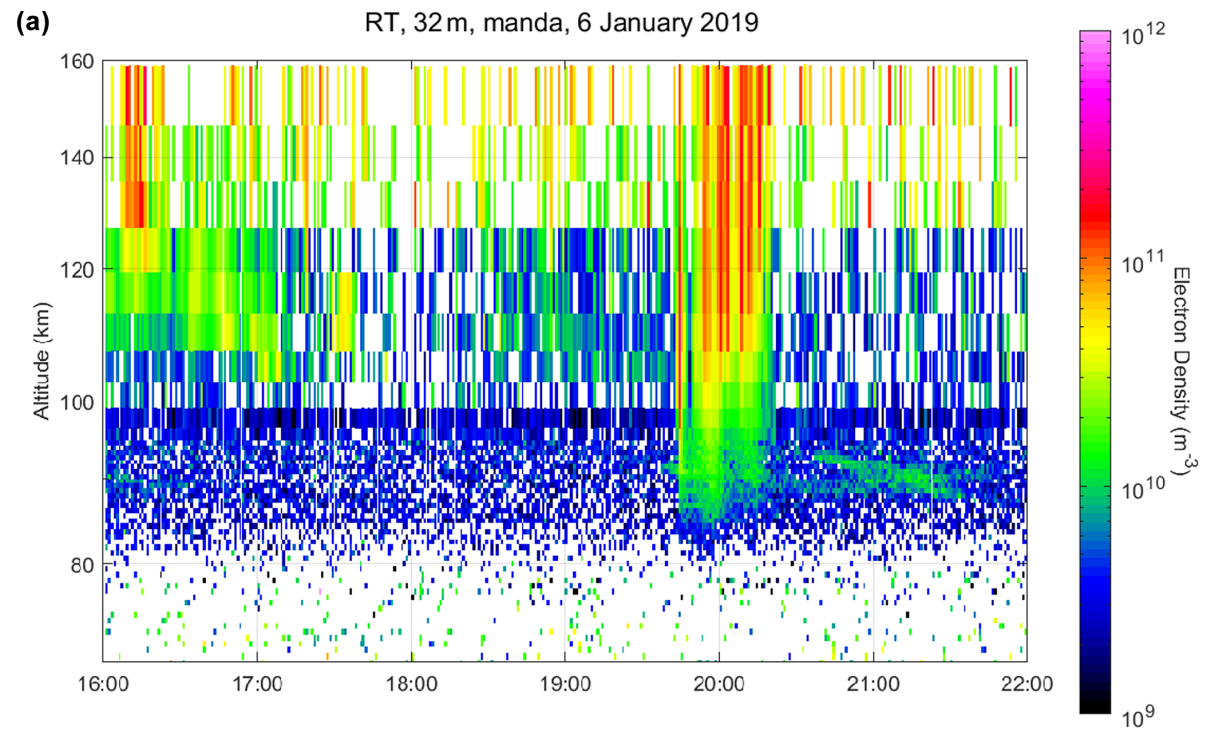

(b)

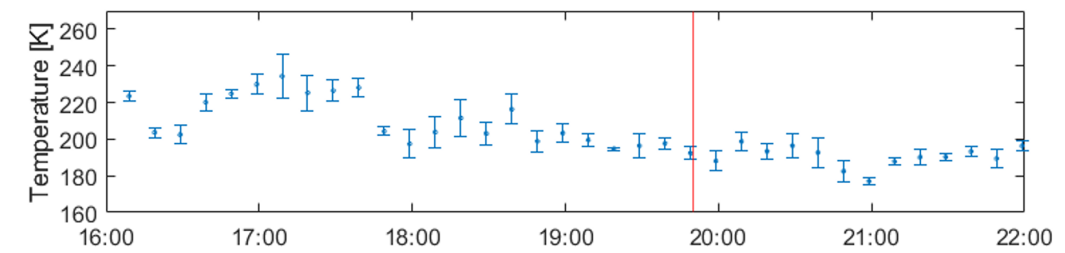

(c)

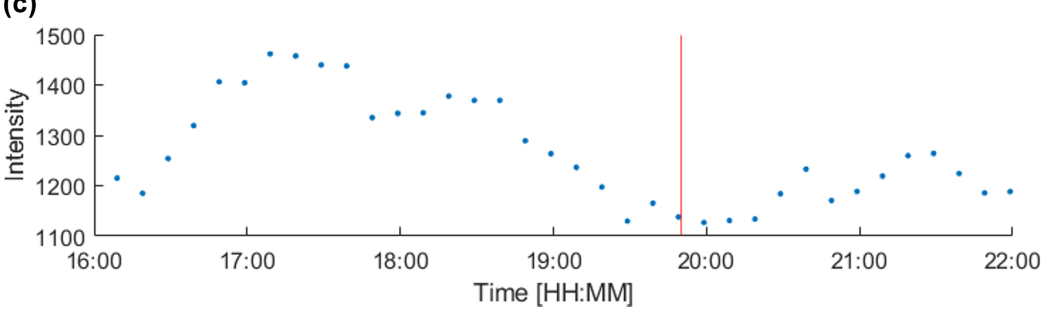

Figure 1. Panel (a) shows the electron density as a function of altitude and time for the manda experiment at 16:00-22:00 UT on 6 January 2019 (tenth event). The particle precipitation event starts at 19:50 UT (vertical red line). The data are post-integrated to $0.6 \mathrm{~km}$ resolution at $80 \mathrm{~km}$ height to $3-4 \mathrm{~km}$ resolution at $100 \mathrm{~km}$ height and $60 \mathrm{~s}$ time resolution. Panel (b) contains $\mathrm{OH}$ temperature data and panel (c) displays the evolution of the relative band brightness, both in $30 \mathrm{~min}$ averages at every $10 \mathrm{~min}$.

Table 1. Airglow temperature values (in Kelvin in $30 \mathrm{~min}$ averages) before, at and after the event onsets for each EPP event. $T_{0}$ indicates the point closest to the event onset. The data points are $10 \mathrm{~min}$ apart. For instance, $T_{-1}$ refers to the data point 10 min before $T_{0}$. All temperature values are accompanied by the fitting error. The last columns indicate the observed change in the temperature over the EPP onset. The points compared in the $\Delta T$ column are $T_{-1}$ to $T_{+2}$ (as $T_{-1}$ is not available for the first event $T_{-2}$ used).

\begin{tabular}{llrrrrrrl}
\hline No. & Event date (UT) & \multicolumn{1}{c}{$T_{-2}(\mathrm{~K})$} & \multicolumn{1}{c}{$T_{-1}(\mathrm{~K})$} & $T_{0}(\mathrm{~K})$ & $T_{+1}(\mathrm{~K})$ & $T_{+2}(\mathrm{~K})$ & $\Delta T(\mathrm{~K})$ & Classification \\
\hline 1 & 29 Dec 2007 23:30 & $225 \pm 6$ & & & $188 \pm 16$ & $185 \pm 12$ & -40 & Decreasing \\
2 & 28 Feb 2008 02:50 & $227 \pm 10$ & $215 \pm 21$ & $187 \pm 18$ & $207 \pm 6$ & $202 \pm 21$ & -13 & Decreasing \\
3 & 6 Dec 2013 21:50 & $224 \pm 9$ & $219 \pm 3$ & $212 \pm 4$ & $210 \pm 0$ & $196 \pm 3$ & -23 & Decreasing \\
4 & 21 Jan 2014 15:20 & $229 \pm 8$ & $222 \pm 2$ & $214 \pm 4$ & $211 \pm 4$ & $212 \pm 5$ & -10 & Decreasing \\
5 & 24 Jan 2014 02:10 & $212 \pm 5$ & $210 \pm 5$ & $198 \pm 2$ & $199 \pm 3$ & $198 \pm 2$ & -12 & Decreasing \\
6 & 24 Jan 2014 15:20 & $218 \pm 14$ & $214 \pm 9$ & $212 \pm 9$ & $217 \pm 7$ & $217 \pm 11$ & +3 & Stable \\
7 & 25 Jan 2014 02:40 & $228 \pm 6$ & $221 \pm 4$ & $224 \pm 2$ & $221 \pm 5$ & $224 \pm 3$ & +3 & Stable \\
8 & 6 Feb 2016 19:50 & $194 \pm 4$ & $195 \pm 7$ & $187 \pm 10$ & $184 \pm 6$ & $182 \pm 4$ & -13 & Decreasing \\
9 & 5 Jan 2019 21:50 & $202 \pm 3$ & $203 \pm 8$ & $198 \pm 5$ & $194 \pm 7$ & $210 \pm 7$ & +7 & Stable \\
10 & 6 Jan 2019 19:50 & $196 \pm 6$ & $198 \pm 3$ & $192 \pm 3$ & $188 \pm 5$ & $199 \pm 5$ & +1 & Stable \\
\hline
\end{tabular}



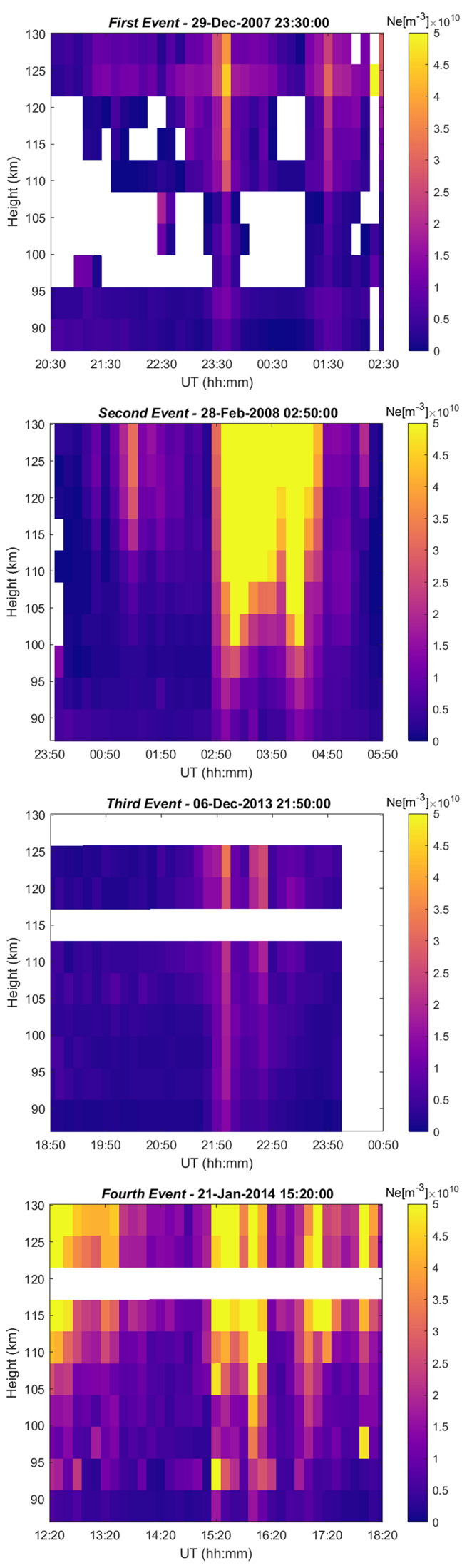
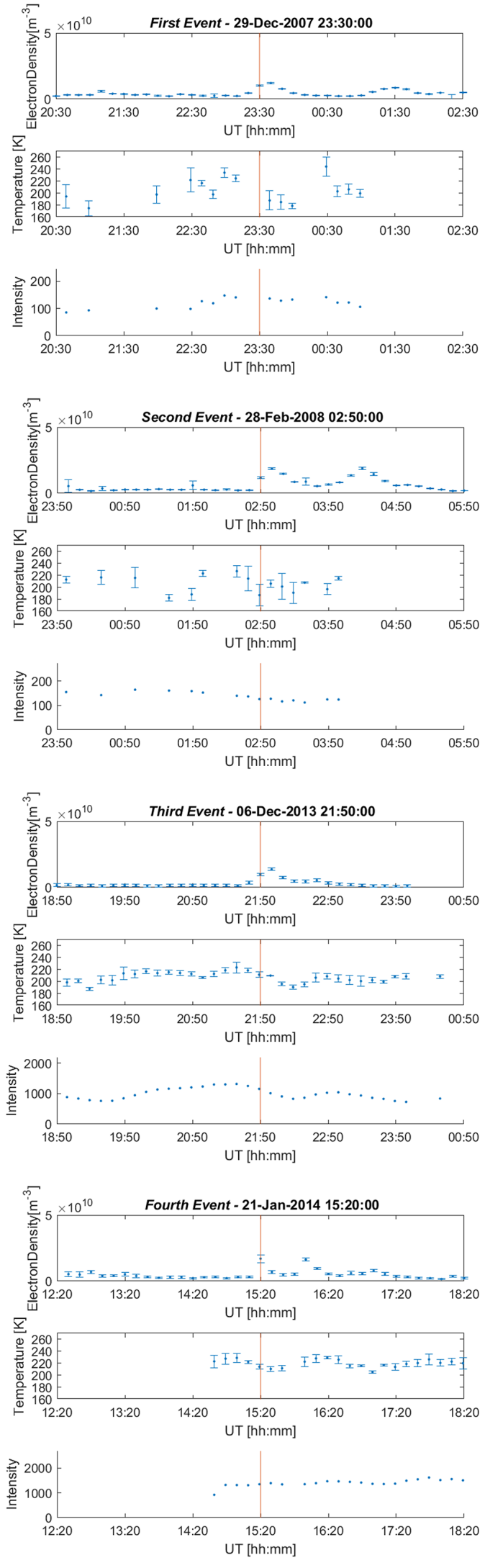

Figure 2. 

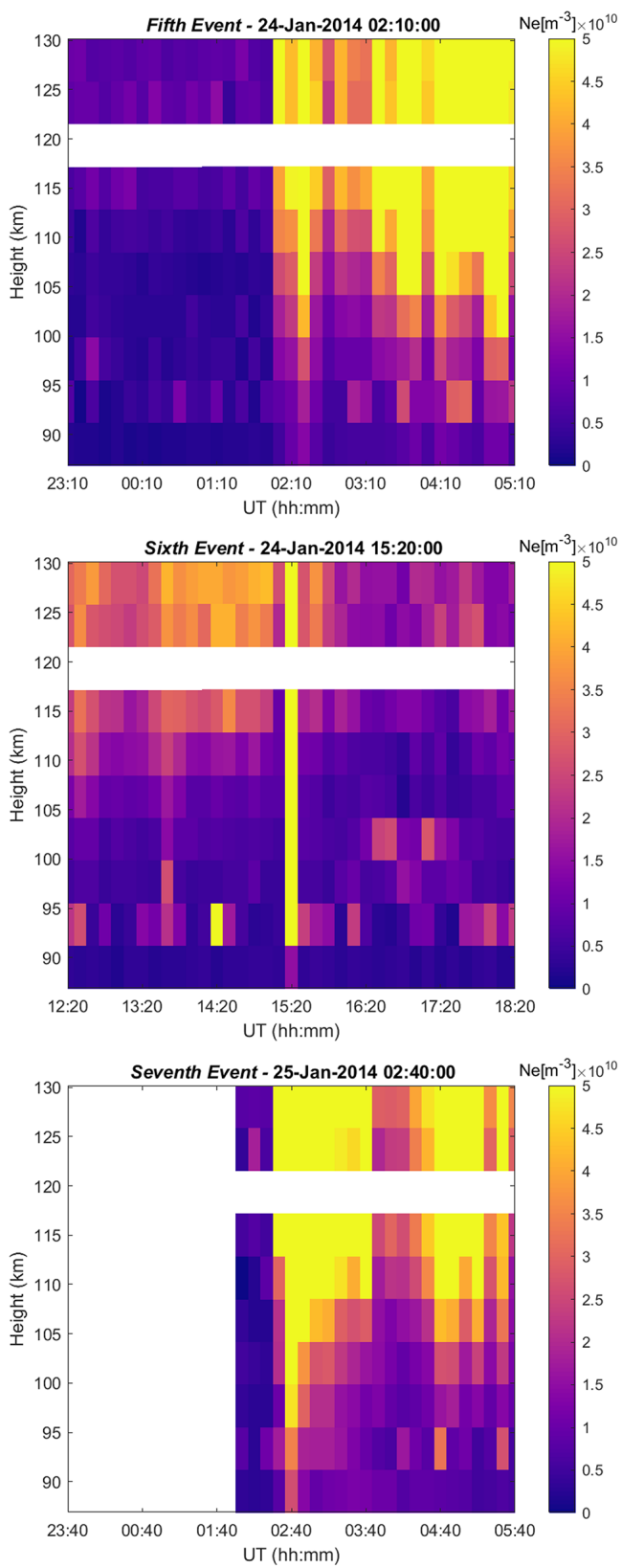

Figure 2.

onset time and recovers within an hour after the onset. Here the $T_{-1}$ temperature point is missing. Therefore the previous point is used as a pre-EPP reference. The relative $\mathrm{OH}(6-2)$ band intensity is 148 before the event and diminishes to 129 over the EPP onset.

- The second event starts at 02:50 UT on 28 February 2008 . The electron density enhancement is detected in the height range of $91-94 \mathrm{~km}$ with an onset time value of $1.2 \times 10^{10} \mathrm{~m}^{-3}$. The precipitation lasts for about $40 \mathrm{~min}$ and is followed by another increase lasting for about 50 min (from 04:00 until 04:50 UT). An airglow
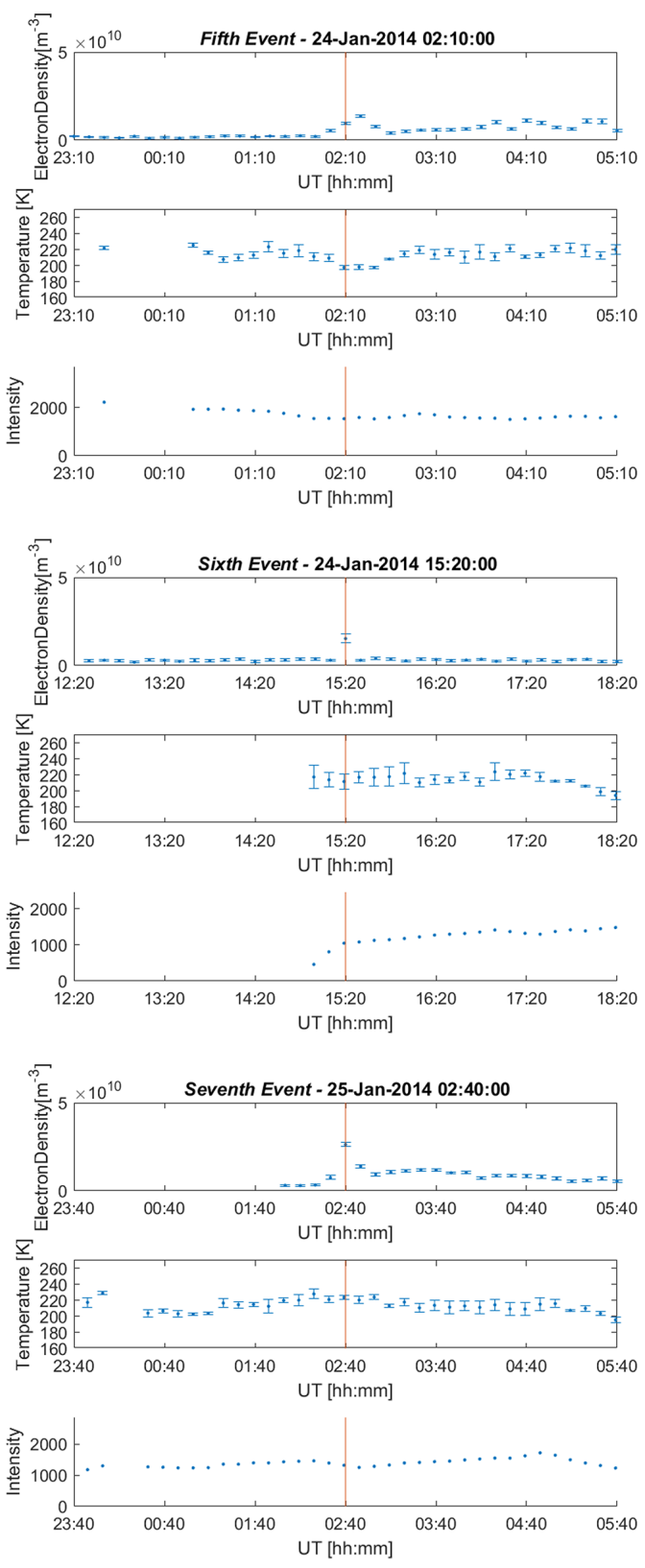

temperature decrease of $13 \mathrm{~K}$ (from 215 to $202 \mathrm{~K}$ ) is observed at the EPP onset time. The decrease is large but still within the error bars. The relative $\mathrm{OH}(6-2)$ band intensity decreases gradually from $2 \mathrm{~h}$ before the event until the event onset time.

Thus, during this event the intensity behaviour is much smoother than that of the temperature. Little or no correlation is seen between the two parameters.

- The third event starts at 21:50 UT on 6 December 2013. It is detected in the altitude range of $87-90 \mathrm{~km}$ with an electron density value of $9.9 \times 10^{9} \mathrm{~m}^{-3}$. The temper- 

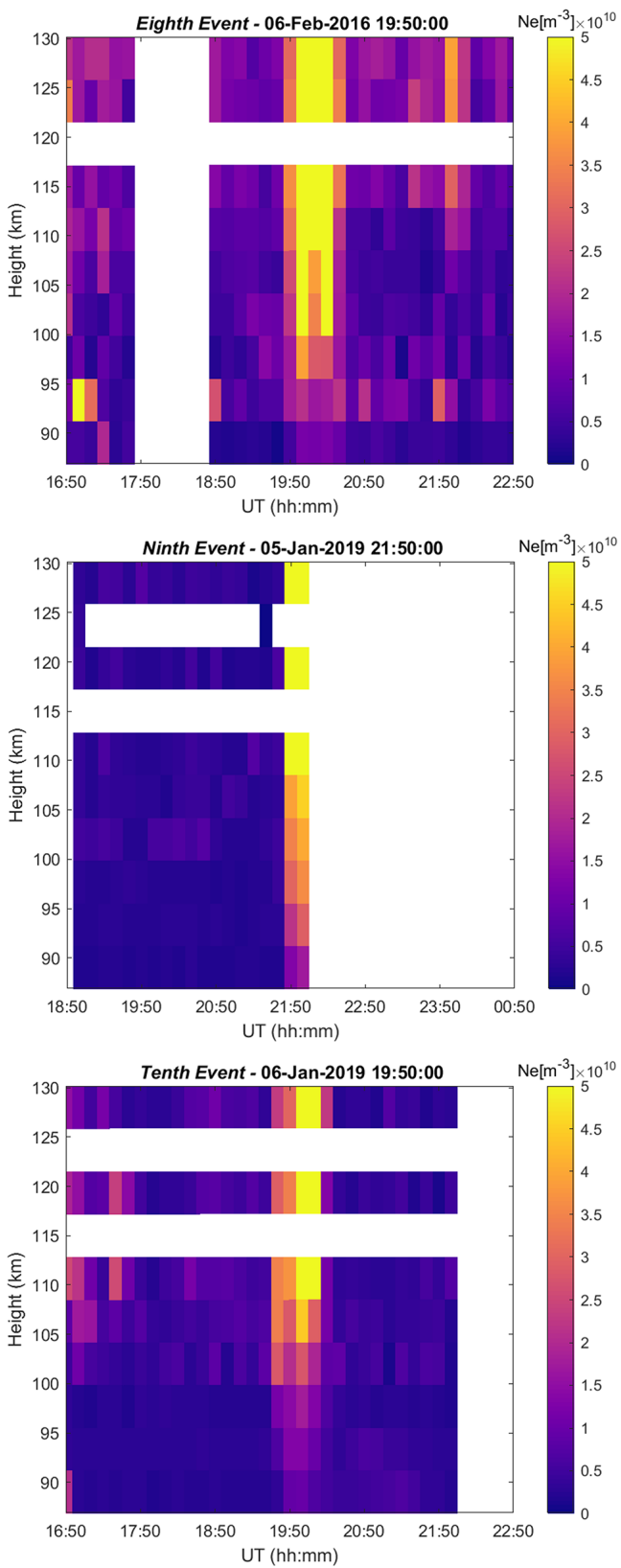
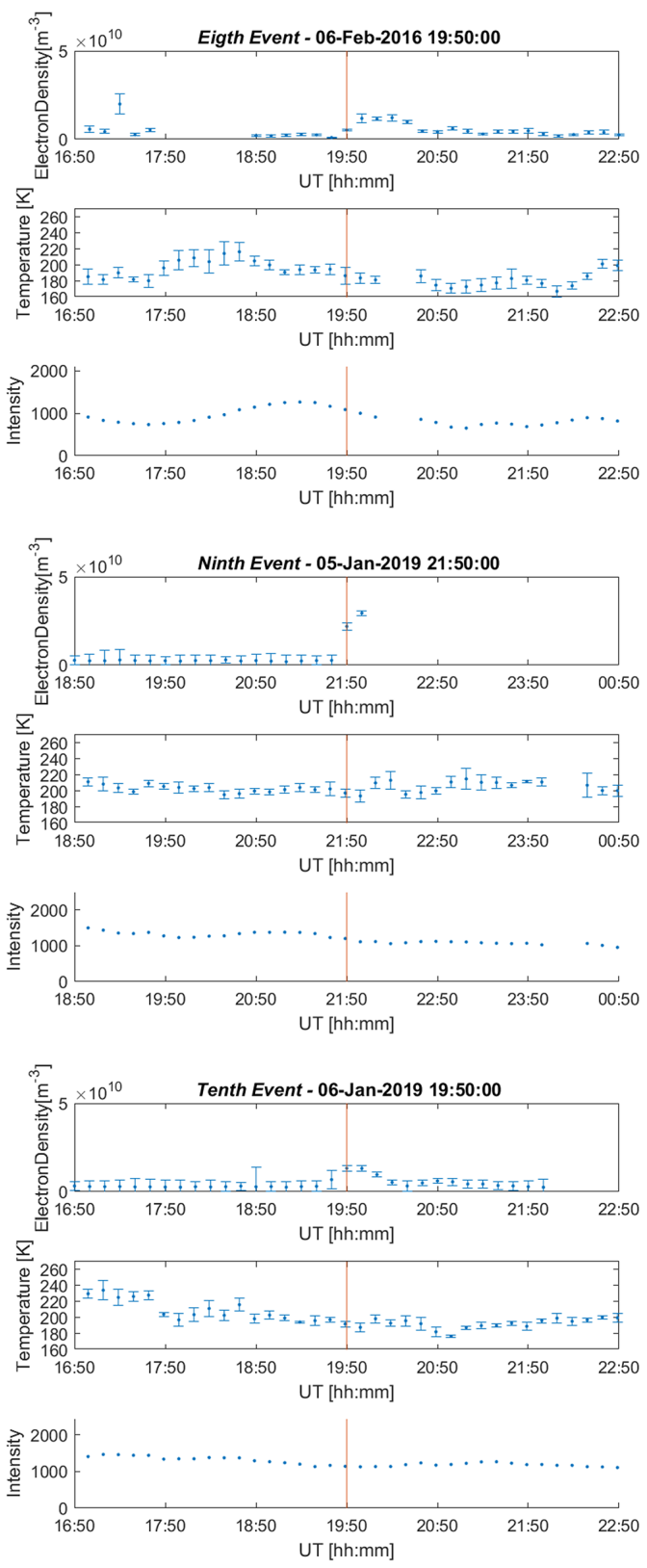

Figure 2. The left column shows the averaged electron density as a function of altitude and time. The right column illustrates the electron density time evolution in the height range where the electron density enhancement was detected. The temporal evolution of the airglow temperature (middle panel) and the relative $\mathrm{OH}(6-2)$ band intensity in arbitrary units (bottom panel) are also included. The temperature and intensity measurements are shown at the end of their half-hour integration time. All time axes are given from $3 \mathrm{~h}$ before to $3 \mathrm{~h}$ after the EPP onset, which takes place in the middle of the plot. The white gaps in the electron density plots indicate missing data.

ature decreases by $23 \mathrm{~K}$ (from 219 to $196 \mathrm{~K}$ ) over the event onset time. Both temperature and electron density values recover within an hour. The relative band intensity peaks at 1320 half an hour before the onset, decreases to 1011 at the onset and minimizes at 864 after the electron density maximum. A positive correlation between the temperature and band intensity is found in this case.
- The fourth event starts at 15:20 UT on 21 January 2014, detected in the altitude range of $87-90 \mathrm{~km}$ with an electron density value of $1.7 \times 10^{10} \mathrm{~m}^{-3}$. The precipitation continues for about an hour. The temperature falls by $10 \mathrm{~K}$ (from 222 to $212 \mathrm{~K}$ ) over the onset time. The electron density falls within the next half hour but increases again to $1.6 \times 10^{10} \mathrm{~m}^{-3}$ about $40 \mathrm{~min}$ after the onset. The temperature values increase to its background level 
at the time the electron density peaks a second time. The relative band intensity is stable. However, the slight intensity variations coincide with the peaks and drops in the temperature evolution.

- The fifth event starts at 02:10 UT on 24 January 2014 at an altitude range of $87-90 \mathrm{~km}$. The electron density at the precipitation onset is $9.5 \times 10^{9} \mathrm{~m}^{-3}$ and stays elevated for about $2 \mathrm{~h}$ after the initial enhancement, which only lasts for about $30 \mathrm{~min}$. The mesopause temperature undergoes a decrease of about $12 \mathrm{~K}$, from $210 \mathrm{~K}$ prior to the event to $198 \mathrm{~K}$ after the EPP onset. The temperature recovery follows that of the initial enhancement in electron density. The $\mathrm{OH}(6-2)$ band intensity decreases from 1890 to 1551 already an hour prior to the EPP onset. Similar to the temperature evolution, the emission intensity recovers within half an hour after the onset. There is a mild positive correlation between the temperature and band intensity values.

- The sixth event commences at 15:20 UT on 24 January 2014 in the altitude range of $87-90 \mathrm{~km}$. The electron density enhancement is seen in a single profile only (10 min lifetime), with the value of $1.5 \times 10^{10} \mathrm{~m}^{-3}$. The mesopause temperature undergoes mild fluctuations, but all changes are well within the errors and, thus, this event is classified as stable. The relative $\mathrm{OH}$ band intensity strongly increases (from 460 to 1079) during half an hour before the onset. After the event onset a more steady and gentle increase in the emission intensity is seen. A more persistent mesospheric electron density enhancement below $95 \mathrm{~km}$ may refer to an evolution of a sporadic E layer which can affect the temperature evolution. Furthermore, the short lifetime of the electron density enhancement is a good candidate to explain the temperature stability.

- The seventh event begins at 02:40 UT on 25 January 2014. It is detected at an altitude range of $87-$ $90 \mathrm{~km}$ with an electron density value of $2.6 \times 10^{10} \mathrm{~m}^{-3}$. The electron density enhancement is strong for about $20 \mathrm{~min}$ and remains at an elevated level for the next $2 \mathrm{~h}$. The mesopause temperature stays stable over the event onset. The $\mathrm{OH}$ band intensity values also stay constant with respect to the intensities an hour before the EPP event.

- The eighth event is detected at 19:50 on 6 February 2016 in the altitude range of $87-90 \mathrm{~km}$ with an electron density value of $5.2 \times 10^{9} \mathrm{~m}^{-3}$. This increase in precipitating flux lasts for $50 \mathrm{~min}$. The mesopause temperature decreases by $13 \mathrm{~K}$ from the pre-EPP level of $195 \mathrm{~K}$ to the post-EPP level of $182 \mathrm{~K}$. Comparing the same time steps, the emission intensity decreases from 1164 to 911 in correlation with the temperature.
- The ninth event commences at 21:50 on 5 January 2019 at the altitude of $91-94 \mathrm{~km}$ with an electron density value of $2.2 \times 10^{10} \mathrm{~m}^{-3}$. The electron density measurements are only available until $10 \mathrm{~min}$ after the onset time but display a steep increase until then. The temperature increase at the EPP event onset is, however, within the uncertainty and therefore classified as stable. The relative band intensity is 1372 half an hour before the onset, 1201 at the onset time and 1058 half an hour after onset, which is a more systematic decrease than what is seen in the temperature.

- The tenth event starts at 19:50 UT on 6 January 2019 and is detected in the altitude range of $91-94 \mathrm{~km}$. The electron density at the EPP onset is $1.3 \times 10^{10} \mathrm{~m}^{-3}$, and the enhancement lasts for about $30 \mathrm{~min}$. The mesopause temperature does not decrease when comparing the preEPP level to that when the electron density is first enhanced. The relative $\mathrm{OH}(6-2)$ band intensity at the event onset is 54 units higher than the level before the event onset time but stays otherwise constant throughout the analysis window.

The temperature dependence on the electron density for EPP events with temperature decrease is shown as a scatter plot in Fig. 3a. The scatter plot includes all simultaneous temperature and electron density value pairs from $30 \mathrm{~min}$ before to $60 \mathrm{~min}$ after the EPP onset. The result is a mild anti-correlation between the electron density and the airglow temperature with a large range of variation. The correlation coefficient for EPP events with a temperature decrease is -0.2753 . The average temporal evolution of the temperature response is seen in the superposed epoch analysis from $2 \mathrm{~h}$ before to $2 \mathrm{~h}$ after the precipitation onset for all $10 \mathrm{EPP}$ events (panel c). The zero epoch time (EPP onset) shows the lowest temperature in the median (blue) as well as upper and lower percentile (red) curves. This immediate temperature decrease is of the order of $20^{\circ}$ and recovers within half an hour after the EPP onset. Similarly, the scatter plot of electron density and the relative airglow intensity (panel b) suggest a mild negative correlation at brightness values around and larger than 1000 counts. The correlation coefficient for EPP events classified as decreasing is -0.1306 . The median, upper and lower percentiles of the airglow intensity (panel d) show about $15 \%$ decrease at the zero epoch time, which recovers in tandem with the median temperature. The intensities vary in the range from hundreds to thousands.

As it is clear that there are temperature changes before and after the EPP onsets which are of the same order of magnitude as those during the EPP events, we compiled a list of times ("non-events"; see Appendix A) when there are no electron density enhancements reaching the heights below $100 \mathrm{~km}$. This set of non-events is equal in number and mimics the diurnal and seasonal distributions of the EPP events (same days). There were not enough data coverage and quiet conditions during the first and second events, and 

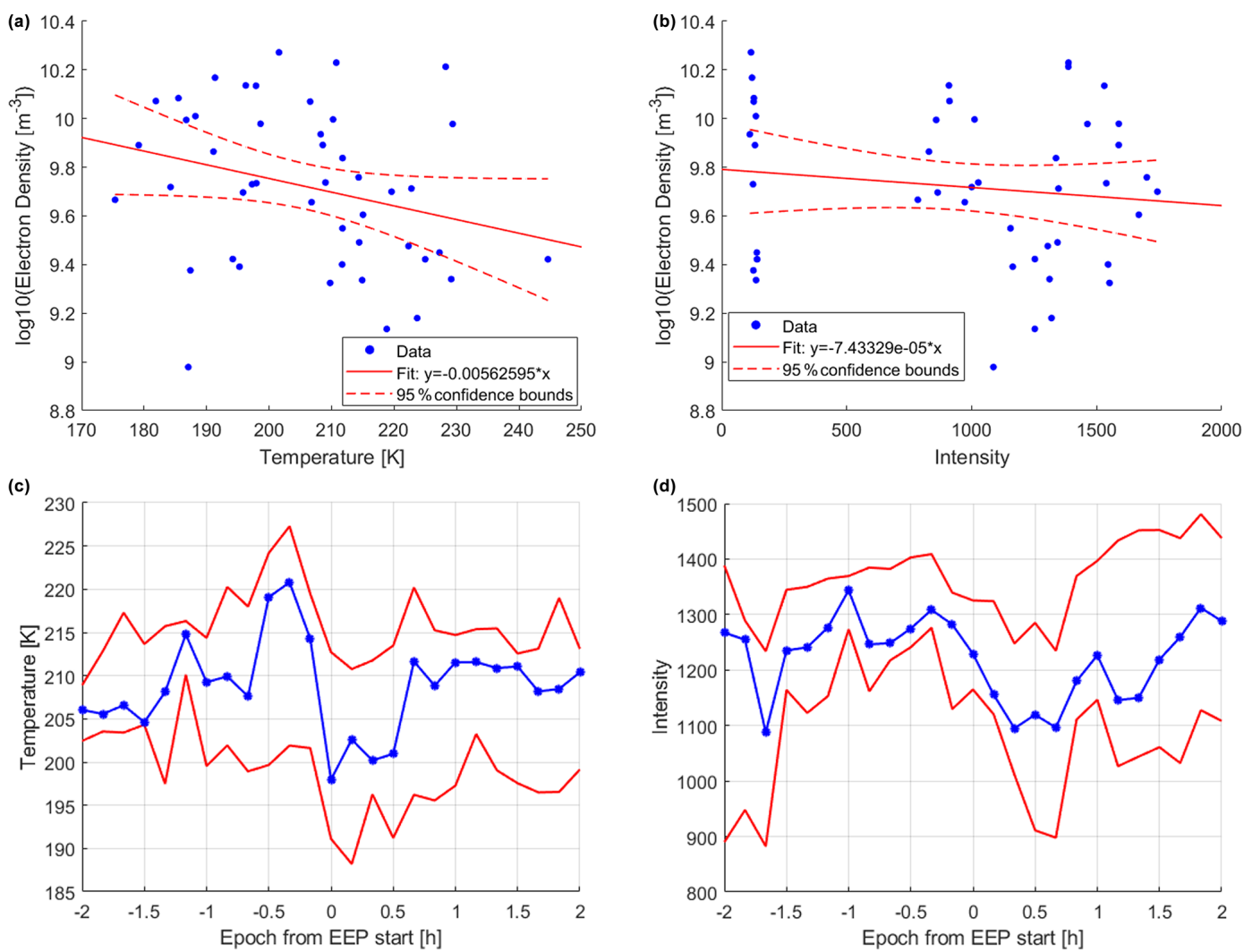

Figure 3. This figure illustrates the average temperature and intensity response to the EPP onset. Panel (a) (panel b) shows a scatter plot of the electron density and the airglow temperature (intensity) values, including data points from half an hour before to $1 \mathrm{~h}$ after the EPP event for the six decreasing events. The regression line with its $95 \%$ confidence bounds is shown in red. The superposed epoch of the airglow temperature in (c) (airglow intensity in d) includes the 25th (lower red line), 50th (blue) and 75th (upper red line) percentiles of the temperature for all 10 events. The first and second events are accompanied by very low-intensity values. To reduce the dominance of these two events, the lower percentile for intensity is set at $35 \%$. The zero epoch time corresponds to the EPP onset. The measurements are chosen closest to the respective epoch time and averaged. Each $30 \mathrm{~min}$ epoch time bin contains 6 to 10 temperature (intensity) values. The variation in the number of data points is due to individual missing data points.

therefore the non-events are chosen on the days of the third to tenth events. The superposed epoch plot for the non-events is shown in Fig. 4. No systematic temperature decrease of the order of tens of degrees at the non-event onset is found. This suggests that it is unlikely to find a median temperature change of over $10^{\circ}$ by coincidence, but aligning the EPP onsets emphasizes the mild effect of decreasing temperature at the EPP onset.

\section{Discussion}

We have found and analysed 10 electron precipitation events which reached the mesopause region and had a good coverage of co-located $\mathrm{OH}$ airglow temperature data. Table 1 shows that 6 of 10 EPP events analysed in this study were accompanied by a decrease in the mesopause temperature by $10-40 \mathrm{~K}$ at the EPP onset. The pre-EPP temperature level (temperature values 10-20 min before the event) varied be- tween 194 and $229 \mathrm{~K}$, and the temperature decreased to the range of $184-211 \mathrm{~K}$.

The winter mesopause is characterized by a large temperature variability (of the order of $10 \mathrm{~K}$, Suzuki et al., 2010b) due to gravity wave propagation. This makes it challenging to isolate any changes as a consequence of any particular driver. The fact that a coherent temperature decrease is seen when the EPP onsets are aligned at zero epoch time does, however, indicate that there is a more systematic response to the particle precipitation, although changes of similar magnitude can occur for other reasons as well. Sudden stratospheric warmings (SSWs), planetary waves, atmospheric tides and the polar vortex strongly affect the mesopause region and its temperature variability (e.g. Harvey et al., 2018); none of these would cause the synchronized temperature changes with EPP onsets. Along with gravity waves, these sources can be responsible for temperature changes outside the EPP events. Any of these dynamic events may also act simultaneously with some of the EPP events for enhancing or cancelling the 


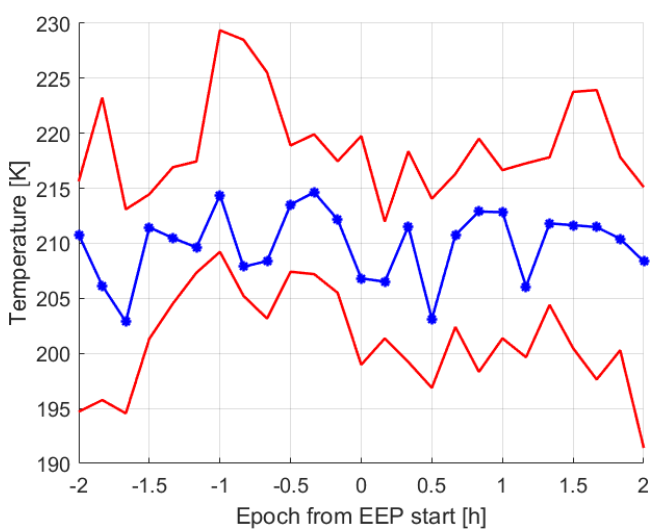

Figure 4. Typical temporal evolution of mesopause temperature without EPP onsets. The superposed epoch of the airglow temperature consists of the 25th (lower red line), 50th (blue) and 75th (upper red line) percentiles of the temperature for times with similar background conditions to the EPP events and on the same days as the EPP events (for dates and times, see Table A1).

EPP-driven signature, which is likely to be the case with the first event, where the temperature decrease is $40 \mathrm{~K}$. Furthermore, the second and tenth events occur within a week of SSW. Around the second event we do not have enough data coverage to see the SSW-related temperature evolution, but in the case of the tenth event about a week-long temperature excursion of the order of $50 \mathrm{~K}$ can be seen in the daily averages (not shown) after SSW on 2 January 2019. Despite the slow SSW effect, the temperature around the EPP onset does not change.

It is thus understandable that there is no consensus on the temperature response to EPP when any minor change is likely to be lost in the highly variable background conditions. The temperature responses found in this study for 6 out of 10 EPP events were larger than $10 \mathrm{~K}$. The short lifetime $(<60 \mathrm{~min})$ of the observed temperature responses does not allow this signature to be detected in analysis utilizing daily averaged temperature data. For instance, the fast temperature decrease and equally quick recovery shown by the superposed epoch analysis (Fig. 3c) would not be seen as a change in daily averaged epoch. It may not be significant in the hourly averaged data.

The first event (top panel of Fig. 2) shows a strong decrease in the mesopause temperature at the time of the EPP onset. Similarly, in the third event and eighth event quiet ionospheric conditions (low electron density) are seen prior to the EPP onset, and the connection between the electron density enhancements and the temperature changes is clear. This is a typical behaviour in our set of events. It is further demonstrated by the anti-correlation between the airglow temperature and the electron density seen in Fig. 3a.

In the second, fourth and fifth events the short-lasting electron density enhancements are followed by longer-lasting but elevated levels of electron densities. In all these cases the electron fluxes reaching the E-region heights (above $100 \mathrm{~km}$ ) are high for about $2 \mathrm{~h}$ after the EPP event, but only at the very beginning of the precipitation event did they reach the altitudes below $100 \mathrm{~km}$. Consequently, the temperature behaviour is smooth and steady apart from the short-term change around the EPP onset. The second event shows the same characteristics of an apparent decrease. However, the decrease is of the order of the fitting error and thus includes a large uncertainty.

Our sixth, seventh, ninth and tenth events were classified as stable in terms of the mesospheric temperature response. The electron density increase in the sixth event has the shortest lifetime of all our events, as it is seen in one $10 \mathrm{~min}$ profile only. Similarly, the tenth event is short-lived. The lifetime of the electron bombardment may thus be the key factor determining whether a measurable neutral temperature response is seen. Based on the events analysed in this study, the temperature change does not directly relate to the precipitating particle flux. More determining factors can be the characteristic energy and the lifetime of the EPP event as well as the ionospheric conditions before the EPP onset. The precipitation properties should be investigated in the future to better understand the determining factors of the EPP impact.

A statistical study on high-latitude $\mathrm{OH}$ airglow temperatures and emission intensities by Shepherd et al. (2007) shows a strong positive correlation between the two parameters on the timescales from hours to seasons. This is explained by vertical motion of the airglow layer driven by atmospheric dynamics. For instance, as an airglow layer undergoes downward motion, the adiabatic heating increases its temperature. The lower peak emission height coincides with a higher mixing ratio of oxygen and, therefore, enhances the production of the excited $\mathrm{OH}$. The temperature changes observed in our study take place on shorter timescales. The correlation between the $\mathrm{OH}(6-2)$ temperature and the relative band intensity of $30 \mathrm{~min}$ averaged data can be visually inspected in Fig. 2. While a positive correlation can be seen between the two parameters in the case of the third, fifth and eighth events, only mild anti-correlation across the entire event set was found (shown in Fig. 3). As the scatter plots include data points from $30 \mathrm{~min}$ before to $60 \mathrm{~min}$ after the onset time, the lack of scatter correlation suggests that there is no larger-scale or periodic coherent behaviour between temperature and brightness within the examined time period. The synchronous decrease in temperature and brightness seen in the epoch curves is a short-term feature, which does not dominate the scatter. A periodic out-of-phase relationship between temperature and brightness, which has been observed for non-EPP conditions (Suzuki et al., 2010a), would result in low correlation but would not explain the synchronous decrease at onset.

An increase in the mesospheric temperature during particle precipitation would agree with the Joule heating effect suggested by earlier studies (Nesse Tyssøy et al., 2010). In fact, a temperature increase of about $10 \mathrm{~K}$ was observed in 
the study by Suzuki et al. (2010b). In our study, however, the mesopause temperature responded to the particle impact with a decrease of about $20 \mathrm{~K}$ in 6 out of 10 events. A way to explain the temperature change Suzuki et al. (2010b) discussed was that the EPP ionization changes the mesospheric chemical composition by decreasing the population of excited $\mathrm{OH}$ at the top of the layer. As a consequence, the peak height of the airglow changes and the temperatures are weighted by lower altitudes than before. The energetic electron impact can dissociate oxygen and ozone molecules in the mesosphere (e.g. Turunen et al., 2016). When less $\mathrm{O}_{3}$ is available, less-excited $\mathrm{OH}$ molecules are produced as ozone is a key ingredient in the production of excited hydroxyl:

$\mathrm{H}+\mathrm{O}_{3} \rightarrow \mathrm{O}_{2}+\mathrm{OH}^{*}\left(v^{\prime} \leq 9\right)$,

where $v^{\prime}$ corresponds to the upper vibrational level of the $\mathrm{OH}$ molecule, which in our case is 6 . The dissociation of molecular oxygen and ozone by energetic electrons can therefore lead to a decrease in the emission of the $\mathrm{OH}$ airglow.

The fitted rotational $\mathrm{OH}$ temperature corresponds to the height of the airglow layer. The peak is assumed to be at about $87 \mathrm{~km}$. If, however, the production of excited $\mathrm{OH}$ is temporarily prohibited at the top part of the airglow layer, the temperature will then represent the layer, which is now centred at lower heights. Depending on the local gradient in the mesospheric temperature profile, this may lead to increased, decreased or unchanged temperature values. In this scenario, the relative $\mathrm{OH}(6-2)$ band intensity would decrease as the airglow layer becomes thinner, which is true for most of the events analysed in this study.

In particular, at the top of the mesosphere, the temperature can vary of the order of $10 \mathrm{~K}$ over a height range of a few kilometres. Mesospheric winter time temperatures are also often constant over a large range of heights, which results in no change in the temperature even if the $\mathrm{OH}$ layer height changes. This may be the case in our events $6,7,9$ and 10, where no obvious temperature change was observed.

According to the superposed epoch behaviour in Fig. 3, a typical temperature decrease at the event onset is about $20 \mathrm{~K}$, while that for the relative band brightness is about $15 \%$. In a Gaussian airglow profile (as for instance depicted by Suzuki et al., 2010b, in their Fig. 4) an intensity reduction of $15 \%$ would correspond to thinning of the airglow layer by about $2 \mathrm{~km}$ and a gradient in the temperature profile of about $10 \mathrm{~K} / \mathrm{km}$. While no measured mesospheric temperature profiles were available during the events analysed here, browsing polar night temperature measurements by SABER/TIMED spacecraft showed that a decreasing temperature of $5-10 \mathrm{~K} / \mathrm{km}$ over the airglow altitude range is not uncommon. However, the first event with a temperature decrease of $40 \mathrm{~K}$ is not realistically explained by the depletion of $\mathrm{OH}$ alone.

The superposed epoch behaviour of non-EPP times which mimic the same diurnal and seasonal distribution as our EPP events (see Fig. 4) does not show any transient change of the order of some $10 \mathrm{~K}$ at or around the zero epoch time. This suggests that the temperature change of the order of some $10 \mathrm{~K}$ is unlikely to appear as a median behaviour by coincidence but is, in the case of this study, a result of aligning the EPP onsets.

Our results together with the previous results by Suzuki et al. (2010b) present an inconsistent temperature response to EPP. Therefore, a larger number of events should be collected and examined to investigate which precipitation parameters and background ionospheric conditions play key roles in the final outcome. Furthermore, an immediate temperature response and its fast recovery suggest that the longer-term and larger-scale heat balance in the mesosphere is little affected by EPP unless the actual precipitation has a substantial lifetime (hours to days).

\section{Conclusions}

A total of $10220 \mathrm{~h}$ of electron density measurements were browsed in the search for enhancements due to energetic particle precipitation (EPP) events with simultaneous temperature calculations from $\mathrm{OH}$ airglow measurements. A total of 10 events of electron density enhancements were found and analysed in this study. Although the number of events is not statistically sound, the results do systematically point to a short-term EPP effect on neutral temperature based on colocated measurements and, in particular, direct electron precipitation measurements. We searched for any coherent behaviour between the electron density enhancements at the Dregion heights and the mesopause temperature. The response of the mesopause temperature to the EPP energy deposition is predominately ( 6 out of 10 events) an immediate decrease of 10-40 K, which recovers within less than $60 \mathrm{~min}$ after the EPP onset. In case of four events, the temperature change was only a few degrees and well within the uncertainty. Our findings together with a temperature increase in a previous study suggest that an EPP ionization may decrease the production of the excited $\mathrm{OH}$ at the top of the airglow layer. As a consequence, the airglow layer becomes thinner, the peak height is reduced and the airglow temperatures correspond to lower altitudes. Investigating the change in the relative $\mathrm{OH}(6-2)$ band intensity shows a decrease during the majority of our EPP events, thus supporting the thinning scenario as a valid mechanism for changing the measured temperature. Furthermore, the relative $\mathrm{OH}$ brightness values are only poorly correlated with the temperatures on the timescales of a few hours, which is not in agreement with purely dynamically driven temperature changes. Four events showing no change in temperature may indicate that the mesospheric temperature stays constant over a larger range of heights. Given the short-lived characteristic of observed atmospheric temperature changes, EPP is unlikely to have climate effects except for long-lasting events. 


\section{Appendix A}

Table A1. As a comparison data set, some dates for times without an EPP onset are given here. The dates have been chosen with similar background conditions to the EPP events (on the same days).

\begin{tabular}{ll}
\hline No. & Event date (UT) \\
\hline 1 & 6 December 2013 19:00 \\
2 & 21 January 2014 01:00 \\
3 & 21 January 2014 20:00 \\
4 & 24 January 2014 20:00 \\
5 & 25 January 2014 01:00 \\
6 & 25 January 2014 16:00 \\
7 & 6 February 2016 19:00 \\
8 & 5 January 2019 19:00 \\
9 & 6 January 2019 11:30 \\
10 & 6 January 2019 18:00 \\
\hline
\end{tabular}


Data availability. Ebert-Fastie Spectrometer data are available from the KHO website (http://kho.unis.no, last access: 30 June 2020, the Kjell Henriksen Observatory, University Centre in Svalbard). EISCAT data are available from the EISCAT schedule website (https://portal.eiscat.se/schedule/, last access: 30 June 2020, EISCAT Scientific Association) and are the intellectual property of the EISCAT Scientific Association. The EISCAT raw data files are analysed by using the Grand Unified Incoherent Scatter Design and Analysis Package (GUISDAP) (Lehtinen et al., 1996).

Author contributions. FE carried out the analysis of the data and the writing of the paper. NP proposed the idea of the study, fitted and pre-analysed the airglow temperature data, shared her expertise, and together with NI took part in the discussions, interpretations, planning and structure of the work. LB advised and helped describe and analyse the EISCAT data. All the authors helped in the writing process with comments, suggestions and edits on the paper.

Competing interests. The authors declare that they have no conflict of interest.

Disclaimer. The data and figures have been used in the MSc thesis by Florine Enengl, available through http://kth.diva-portal.org/ (last access: 30 June 2020).

Publisher's note: Copernicus Publications remains neutral with regard to jurisdictional claims in published maps and institutional affiliations.

Special issue statement. This article is part of "Special Issue on the joint 19th International EISCAT Symposium and 46th Annual European Meeting on Atmospheric Studies by Optical Methods". It is a result of the 19th International EISCAT Symposium 2019 and 46th Annual European Meeting on Atmospheric Studies by Optical Methods, Oulu, Finland, 19-23 August 2019.

Acknowledgements. The authors thank Fred Sigernes and Mikko Syrjäsuo for the maintenance of the $\mathrm{OH}$ airglow spectrometer. EISCAT is an international association supported by research organizations in China (CRIRP), Finland (SA), Japan (NIPR and ISEE), Norway (NFR), Sweden (VR), and the United Kingdom (UKRI). The authors thank Ingemar Häggström for his assistance with the EISCAT data.

Financial support. The work by Noora Partamies and Lisa Baddeley is supported by the Research Council of Norway (NRC) under CoE contract 223252, and Noora Partamies is further supported by NRC contract 287427.
Review statement. This paper was edited by Daniel Whiter and reviewed by David Newnham and four anonymous referees.

\section{References}

Andrews, D. G.: An Introduction to Atmospheric Physics, 2nd edn., Cambridge University Press, Cambridge, https://doi.org/10.1017/CBO9780511800788, 2010.

Blelly, P. L., Alcaydé, D., and van Eyken, A. P.: A new analysis method for determining polar ionosphere and upper atmosphere characteristics from ESR data: Illustration with IPY period, J. Geophys. Res.-Space, 115, A09322, https://doi.org/10.1029/2009JA014876, 2010.

Cho, Y. M. and Shepherd, G. G.: Correlation of airglow temperature and emission rate at Resolute Bay $\left(74.68^{\circ} \mathrm{N}\right)$, over four winters (2001-2005, Geophys. Res. Lett., 33, L06815, https://doi.org/10.1029/2005GL025298, 2006.

Cresswell-Moorcock, K., Rodger, C. J., Kero, A., Collier, A. B., Clilverd, M. A., Haggstrom, I., and Pitkanen, T.: A reexamination of latitudinal limits of substorm-produced energetic electron precipitation, J. Geophys. Res.-Space, 118, 6694-6705, https://doi.org/10.1002/jgra.50598, 2013.

Gavrilyeva, G. and Ammosov, P.: Influence of geomagnetic activity on mesopause temperature over Yakutia, Atmos. Chem. Phys., 18, 3363-3367, https://doi.org/10.5194/acp-183363-2018, 2018.

Harvey, V. L., Randall, C. E., Goncharenko, L., Becker, E., and France, J.: On the Upward Extension of the Polar Vortices Into the Mesosphere, Journal of geophysical research, Atmospheres, 123, 9171-9191, https://doi.org/10.1029/2018JD028815, 2018.

Holmen, S., Dyrland, M., and Sigernes, F.: Mesospheric temperatures derived from three decades of hydroxyl airglow measurements from Longyearbyen, Svalbard $\left(78^{\circ} \mathrm{N}, 15^{\circ} \mathrm{E}\right)$, Acta Geophys., 62, 302-315, https://doi.org/10.2478/s11600-013-0159-4, 2014.

Holmen, S. E., Dyrland, M., and Sigernes, F.: Mesospheric temperatures derived from three decades of hydroxyl airglow measurements from Longyearbyen, Svalbard $\left(78^{\circ} \mathrm{N}\right)$, Acta Geophys., 62, 302-315, https://doi.org/10.2478/s11600-013-0159-4, 2013.

Lehtinen, M. S., Huuskonen, A., and Pirttilä, J.: First experiences of full-profile analysis with GUISDAP, Ann. Geophys., 14, 14871495, https://doi.org/10.1007/s00585-996-1487-3, 1996.

Mulligan, F. J., Dyrland, M. E., Sigernes, F., and Deehr, C. S.: Inferring hydroxyl layer peak heights from ground-based measurements of $\mathrm{OH}(6-2)$ band integrated emission rate at Longyearbyen $\left(78^{\circ} \mathrm{N}, 16^{\circ} \mathrm{E}\right)$, Ann. Geophys., 27, 4197-4205, https://doi.org/10.5194/angeo-27-4197-2009, 2009.

Nesse Tyssøy, H., Stadsnes, J., Sørbø, M., Mertens, C. J., and Evans, D. S.: Changes in upper mesospheric and lower thermospheric temperatures caused by energetic particle precipitation, J. Geophys. Res.-Space, 115, A10323, https://doi.org/10.1029/2010JA015427, 2010.

Rapp, M., Leitert, L., Latteck, R., Zecha, M., Hoffmann, P., Höffner, J., Hoppe, U., La Hoz, C., and Thrane, E. V.: Localized mesosphere-stratosphere-troposphere radar echoes from the E region at $69^{\circ} \mathrm{N}$ : Properties and physical mechanisms, J. Geophys. Res.Space, 116, A02320, https://doi.org/10.1029/2010JA016167, 2011. 
Shepherd, G., Cho, Y.-M., and Liu, G.: Correlations of mesospheric variability ad their relation to the large-scale circulation during polar winter, J. Atmos. Sol.-Terr. Phy., 69, 2279-2291, https://doi.org/10.1016/j.jastp.2007.06.007, 2007.

Sigernes, F., Shumilov, N., Deehr, C. S., Nielsen, K. P., Svenøe, T., and Havnes, O.: Hydroxyl rotational temperature record from the auroral station in Adventdalen, Svalbard $\left(78^{\circ} \mathrm{N}, 15^{\circ} \mathrm{E}\right)$, J. Geophys. Res.-Space, 108, 1342, https://doi.org/10.1029/2001JA009023, 2003.

Suzuki, H., Tomikawa, Y., Taguchi, M., Nakamura, T., and Tsutsumi, M.: Variations of $\mathrm{OH}$ rotational temperature over Syowa Station in the austral winter of 2008, Earth Planet. Space, 62, 655-661, 2010a.

Suzuki, H., Tsutsumi, M., Nakamura, T., and Taguchi, M.: The increase in $\mathrm{OH}$ rotational temperature during an active aurora event, Ann. Geophys., 28, 705-710, https://doi.org/10.5194/angeo-28-705-2010, 2010b.
Tjulin, A.: EISCAT experiments, available at: https://eiscat.se/ wp-content/uploads/2020/09/Experiments_v20200904.pdf last access: 30 June 2020), 2017.

Turunen, E., Kero, A., Verronen, P. T., Miyoshi, Y., Oyama, S.-I., and Saito, S.: Mesospheric ozone destruction by high-energy electron precipitation associated with pulsating aurora, J. Geophys. Res.-Atmos., 121, 11852-11861, https://doi.org/10.1002/2016JD025015, 2016.

Wannberg, G., Wolf, I., Vanhainen, L. G., Koskenniemi, K., Röttger, J., Postila, M., Markkanen, J., Jacobsen, R., Stenberg, A., Larsen, R., Eliassen, S., Heck, S., and Huuskonen, A.: The EISCAT Svalbard radar: A case study in modern incoherent scatter radar system design, Radio Sci., 32, 2283-2307, https://doi.org/10.1029/97RS01803, 1997. 